\title{
Castleman's Disease: a Condition with Protean Manifestations
}

\section{Bernardino Roca}

Hospital General of Castellon, University of Valencia and University Jaume I, Spain

In 1954, Castleman and Towne described for the first time Castleman's disease (CD) as a non-clonal lymph node hyperplasia [1]. The condition is also known with a variety of other descriptive names, including follicular lymphoreticuloma, angiofollicular lymph node hyperplasia, giant cell lymph node hyperplasia, benign giant lymphoma and lymphoid hamartoma. Clinically CD may adopt a unicentric or multicentric presentation. And pathologically it is classified as hyaline vascular, plasmacytic or mixed cellularity types. The hyaline vascular variant is found in most unicentric cases, and the plasmacytic variant is found in most multicentric cases [2]. In the last decades the interest for the disease has increased due to its association with human immunodeficiency virus (HIV) infection [3].

The etiology and pathogenesis of $\mathrm{CD}$ is probably diverse, as the disease itself. Human herpes virus type 8 (HHV-8), also known as Kaposi's sarcoma-associated herpesvirus, is present in almost all cases of CD occurring in HIV infected patients, and also in some cases of CD occurring in HIV-negative patients. Inflammatory mediators are important in the pathogenesis of CD. Among them, human interleukin-6 (IL-6) has been found to be especially relevant, as it may act as a potent stimulus for the proliferation of B cells, and is abundantly expressed in $\mathrm{CD}$ affected tissues. Moreover, experimental studies have shown that increased production of IL-6 can provoke many of the manifestations of CD [4].

Pathologically CD is characterized by architectural changes in lymph nodes that generally affect all compartments. In the hyaline vascular type, lymph node follicles tend to show atrophic germinal centers, with penetrating small hyalinized vessels and follicular dendritic cells. These centers are surrounded by broadened mantle zones composed of concentric rings of small lymphocytes, in an onion skin-like configuration. In the plasmacytic type, lymph node follicles tend to show hyperplastic germinal centers. The interfollicular region characteristically contains sheets of plasma cells, which are polyclonal [5]. These histopathologic features are not specific of $\mathrm{CD}$, and can be seen in other conditions that cause reactive lymph node hyperplasia, such as infectious and rheumatic diseases [6]. Cases of CD with mixed cellularity, both unicentric and multicentric, are also sometimes seen.

$\mathrm{CD}$ is a rare condition, with the real incidence unknown. It occurs equally in women and men, and no race predominance has been observed. The unicentric hyaline vascular type is the most common one and accounts for about two thirds of all cases; this type of CD occurs in all age groups, but seems to be more common in the third decade of life. The plasmacytic type predominantly presents in the sixth decade of life. In HIV-infected subjects CD most commonly presents in the fourth decade of life, and is more prevalent in men than in women. In these patients $\mathrm{CD}$ frequently coexists with Kaposi's sarcoma [7, 8]. Clonal hematologic disorders, including multiple myeloma, amyloidosis, and lymphomas, occur with increased frequency in $\mathrm{CD}$ [5].

The clinical features of CD vary substantially from case to case [9]. The unicentric hyaline vascular type usually presents as one or several enlarged lymph nodes. They may produce local symptoms, such as pain, due to tissue expansion. But they may also be completely asymptomatic and incidentally detected when explorations or tests for unrelated reasons are carried out. The most common sites of presentation are the mediastinum, the abdomen and the axillary and cervical regions, but the disease may appear in virtually any area of the organism. Systemic symptoms and laboratory test abnormalities are rare. On the other hand, in the unicentric plasmacytic type, in addition to enlarged lymph nodes, constitutional symptoms and laboratory abnormalities, similar to those of multicentric $\mathrm{CD}$, are common [10].

In the multicentric plasmacytic type systemic symptoms are common, and often severe. They are the presenting complaint in most cases. The majority of patients have fever, weakness, anorexia, and weight loss. Almost all subjects have multifocal lymphadenopathy. The enlarged lymph nodes are frequently painful. Hepatosplenomegaly is also common, and virtually any organ can be affected [11]. Anemia, especially of chronic disease, is present in most patients, and other

\section{KARGER}

Fax +497614520714

Information@Karger.de

www.karger.com (c) 2011 S. Karger GmbH, Freiburg

0378-584X/11/0348-0412\$38.00/0

Accessible online at:

www.karger.com/onk
Dr. Bernardino Roca

Hospital General of Castellon

University of Valencia and University Jaume I

Catalunya, 33-4, 12004 Castellon, Spain

Tel and fax: +34 964240854

brocav@meditex.es 
common abnormalities are thrombocytopenia, accelerated erythrocyte sedimentation rate, raised C-reactive protein, increased liver enzymes, elevated creatinine, hypoalbuminemia and polyclonal hypergammaglobulinemia [12]. Also characteristic are increased serum levels of IL-6. Bone marrow plasmacytosis is commonly observed.

Image studies frequently display a variety of tissue abnormalities throughout the body, in addition to lymphadenopathy. Calcification is occasionally seen [13, 14]. Contrast enhancement is typical of CD lesions, and fluorodeoxyglucose-positron emission tomography scanning usually reveals low to moderate specific uptake values in affected tissues [15]. A biopsy is necessary to establish the diagnosis.

Unicentric CD, either hyaline vascular or plasmacytic type, is generally treated with excisional surgery or irradiation, but in some cases simple observation may also be adequate. Multicentric $\mathrm{CD}$ almost always requires systemic therapy, which may consist of glucocorticosteroids, thalidomide, retinoic acid, or chemotherapy similar to that used in lymphomas. More recently interferon-alpha, rituximab [16], bortezomib [17], or agents with activity against human IL-6, such as suramin, siltuximab [18] or tocilizumab [19], have been used with variable results [20].

One of the main features of $\mathrm{CD}$ is the protean presentations it may adopt. The disease may present in association with uncommon conditions such as autoimmune phenomena [21], the Crow-Fukase or POEMS syndrome (polyneuropathy, organomegaly, endocrinopathy, monoclonal gammopathy and skin changes) [9,22], pemphigus, lymphocytic interstitial pneumonia, bronchiolitis obliterans, etc.; at times CD may present with atypical features of common diseases, such as persistently high fevers [15], or unusual anemia [21].

In this issue of OnKologie, Weng et al. [23], report on a patient with unicentric $\mathrm{CD}$, hyaline vascular type, who presented with severe iron deficiency-like microcytic anemia that only resolved after effective treatment of $\mathrm{CD}$. Other similar cases of microcytic anemia have already been reported, where iron deficiency was suspected but ruled out with the results of iron metabolism analyses [24]. According to recent studies, hepcidin, a substance necessary for normal absorption and utilization of iron, is the principal suspect of causing such iron deficiency-like anemia in $\mathrm{CD}$, as interleukin-6, a substance commonly increased in $\mathrm{CD}$, reduces hepcidin production by the liver [25]. The normal results of serum interleukin-6 in the patient described by Weng et al., do not completely rule out the mechanism in our view, as interleukin-6 serum levels substantially vary over time [26]. Alternatively, as Weng et al. suggest, the normal interleukin-6 level in their patient might be the explanation that she was not iron-deficient.

\section{Acknowledgements}

Support for the preparation of this work has been provided by the Spanish VACH Cohort and the ISCIII-RETIC (RD06/006).

\section{Disclosure Statement}

The author declares no conflicts of interest regarding the article.

\section{References}

1 Castleman B, Towne VW: Case records of the Massachusetts General Hospital: Case No. 40231 N Engl J Med 1954;250:1001-1005.

2 Roca B: Castleman's Disease. A Review. AIDS Rev 2009;11:3-7.

-3 Stebbing J, Pantanowitz L, Dayyani F, Sullivan RJ, Bower M, Dezube BJ: HIV-associated multicentric Castleman's disease. Am J Hematol 2008;83:498503.

4 Dham A, Peterson BA: Castleman disease. Curr Opin Hematol 2007;14:354-359.

$\checkmark 5$ van Rhee F, Stone K, Szmania S, Barlogie B, Singh Z: Castleman disease in the 21st century: an update on diagnosis, assessment, and therapy. Clin Adv Hematol Oncol 2010;8:486-498.

6 Kojima M, Motoori T, Asano S, Nakamura S: Histological diversity of reactive and atypical proliferative lymph node lesions in systemic lupus erythematosus patients. Pathol Res Pract 2007; 203:423-431.

7 Mylona EE, Baraboutis IG, Lekakis LJ, Georgiou O, Papastamopoulos V, Skoutelis A: Multicentric Castleman's disease in HIV infection: a systematic review of the literature. AIDS Rev 2008;10:25-35.
8 Naresh KN, Rice AJ, Bower M: Lymph nodes involved by multicentric Castleman disease among HIV-positive individuals are often involved by Kaposi sarcoma. Am J Surg Pathol 2008;32:10061012.

9 Dispenzieri A: POEMS syndrome. Blood Rev 2007;21:285-299.

10 Newlon JL, Couch M, Brennan J: Castleman's disease: three case reports and a review of the literature. Ear Nose Throat J 2007;86:414-418.

-11 Coca S, Salas I, Martínez R, Saez MA, Vaquero J: Meningeal Castleman's disease with multifocal involvement: a case report and review of literature. J Neurooncol 2008;88:37-41.

12 Kojima M, Nakamura N, Tsukamoto N, Otuski Y, Shimizu K, Itoh H, Kobayashi S, Kobayashi H, Murase T, Masawa N, Kashimura M, Nakamura S: Clinical implications of idiopathic multicentric Castleman disease among Japanese: a report of 28 cases. Int J Surg Pathol 2008;16:391-398.

13 Jongsma TE, Verburg RJ, Geelhoed-Duijvestijn PH: Castleman's disease: A rare lymphoproliferative disorder. Eur J Intern Med 2007;18:87-89.

14 Enomoto K, Nakamichi I, Hamada K, Inoue A, Higuchi I, Sekimoto M, Mizuki M, Hoshida Y, Kubo T, Aozasa K, Hatazawa J: Unicentric and multicentric Castleman's disease. Br J Radiol 2007;80:e24-e26.
15 Roca B, Torres V: Castleman's disease presenting as fever of unknown origin: diagnostic value of fluorodeoxyglucose-positron emission tomography/computed tomography. Am J Med Sci 2009; 337:295-296.

16 Hoffmann C, Schmid H, Müller M, Teutsch C, van Lunzen J, Esser S, Wolf T, Wyen C, Sabranski M, Horst HA, Reuter S, Vogel M, Jäeger H, Bogner J, Arasteh K: Improved outcome with rituximab in patients with HIV-associated multicentric Castleman disease. Blood 2011;doi:10.1182/blood-201102-333633.

17 Hess G, Wagner V, Kreft A, Heussel CP, Huber C: Effects of bortezomib on pro-inflammatory cytokine levels and transfusion dependency in a patient with multicentric Castleman disease. Br J Haematol 2006;134:544-545.

18 van Rhee F, Fayad L, Voorhees P, Furman R, Lonial S, Borghaei $\mathrm{H}$, Sokol L, Crawford J, Cornfeld M, Qi M, Qin X, Herring J, Casper C, Kurzrock R: Siltuximab, a novel anti-interleukin-6 monoclonal antibody, for Castleman's disease. J Clin Oncol 2010;28:3701-3708.

19 Matsuyama M, Suzuki T, Tsuboi H, Ito S, Mamura M, Goto D, Matsumoto I, Tsutsumi A, Sumida T: Anti-interleukin-6 receptor antibody (tocilizumab) treatment of multicentric Castleman's disease. Intern Med 2007;46:771-774. 
20 El-Osta HE, Kurzrock R: Castleman's disease: from basic mechanisms to molecular therapeutics. Oncologist 2011;16:497-511.

21 Yuzuriha A, Saitoh T, Koiso H, Mitsui T, Uchiumi H, Yokohama A, Handa H, Kojima M, Tsukamoto N, Karaswa M, Murakami H, Nojima Y: Successful treatment of autoimmune hemolytic anemia associated with multicentric Castleman disease by antiinterleukin-6 receptor antibody (tocilizumab) therapy. Acta Haematol 2011;126:147-150.
22 Dispenzieri A: POEMS syndrome: 2011 update on diagnosis, risk-stratification, and management. Am J Hematol 2011;86:591-601.

23 Weng $\mathrm{CH}$, Chen JB, Wang J, Wu CC, Yu Y, Lin TH: Surgically curable non-iron deficiency microcytic anemia: Castleman's disease. Onkologie 2011;34: DOI: 10.1159/000331283.

24 Bejjani J, Lemieux B, Gariepy G, Younan R: Complete anemia reversal after surgical excision of mesenteric hyaline-vascular unicentric Castleman disease. Can J Surg 2009;52:E197-E198.
25 Cherayil BJ, Ellenbogen S, Shanmugam NN: Iron and intestinal immunity. Curr Opin Gastroenterol 2011 Jul 22. Epub ahead of print]

26 Picotte M, Campbell CG, Thorland WG: Day-today variation in plasma interleukin-6 concentrations in older adults. Cytokine 2009;47:162-165. 